\title{
As Comunidades Eclesiais de Base (CEBs) nas narrativas orais e memórias de mulheres na Diocese da Campanha, sul de Minas Gerais, entre os anos de 1980 e 2000
}

\author{
Caroline Aparecida Ferreira \\ Graduada em História pela Universidade Federal de Alfenas
}

(UNIFAL-MG)

\section{Resumo}

Este artigo apresenta os resultados de uma investigação realizada na Diocese da Campanha, no sul de Minas Gerais, sobre o trabalho desenvolvido pelas Comunidades Eclesiais de Base (CEBs), que começaram a operar ali no final dos anos 1980 e que têm como evento principal a Romaria do Trabalhador. A metodologia da história oral foi usada para conhecer as experiências de três mulheres no bispado e para entender como as CEBs adquiriram sentido na vida de cada uma delas, na perspectiva da História das mulheres. Durante a pesquisa, percebeu-se que os principais sujeitos das CEBs, como também havia mostrado Eder Sader (1988), foram e continuam sendo as mulheres, que permanecem, muitas vezes, invisibilizadas. A história oral permitiu que elas mesmas pudessem falar sobre suas trajetórias e sobre o papel da Igreja na vida das comunidades em que vivem, além de sua própria identidade como fiéis influenciadas pela Teologia da Libertação, muito forte na América Latina. Por meio das entrevistas foi possível analisar alguns aspectos apontados por Maria Aparecida, Helena Maria e Maria Lucely, que serão explorados ao longo do artigo, tais como a questão de gênero dentro da Igreja, a importância dada por elas à cultura popular em suas ações e a relação entre a memória individual e a memória coletiva.

Palavras-chave CEBs - Mulheres - História oral - Memória - Cultura popular.

Submissão

$05 / 05 / 2020$

Aprovação

$3 \mathrm{I} / 07 / 2020$

Publicação

26/03/202I 


\title{
The Basic Ecclesial Communities (BECs) in the Oral Narratives and Memories of Women in the Diocese of the City of Campanha, South of Minas Gerais, between 1980 and 2000
}

\begin{abstract}
This article presents the results of an investigation carried out in the Diocese of the city of Campanha, in southern Minas Gerais, on the work developed by the Basic Ecclesial Communities (BECs), that began operating there in the late 1980 os and which have as main event the Pilgrimage of Workers. The oral history methodology was used to know the experiences of three women in the bishopric and to understand how the BECs gained meaning in the life of each of them, from the perspective of the history of women. During the research, it was noticed that the main subjects of the BECs, as also shown by Eder Sader (1988), were and remain women, who often remain invisible. Oral history allowed them to talk about their trajectories and the role of the Church in the daily lives of the communities in which they live, in addition to their own identity as a true influenced by Liberation Theology, very strong in Latin America. Through the interviews it was possible to analyse some aspects pointed out by Maria Aparecida, Helena Maria and Maria Lucely, which will be explored throughout the article, such as the issue of gender within the Church, the importance given by them to popular culture in their actions and the relationship between individual memory and collective memory.
\end{abstract}

Keywords BECs - Women - Oral history - Memories - Popular culture.

\section{Las Comunidads Eclesiales de Base (CEBs) en narrativas orales y memorias de mujeres de la Campanha Diócesis, al sur de Minas Gerais, entre 1980 y 2000}

\section{Resumen}

Este artículo expone los resultados de una investigación realizada en la Diócesis da Campanha, al sur de Minas Gerais, acerca los trabajos cumplidos por las Comunidades Eclesiales de Base (CEBs) que comenzó a trabajar allí en finales dela década de 1980 y cuyo acontecimiento principal es la Peregrinación de lo Trabajador. La metodología de la historia oral se usó para conocer las experiencias de tres mujeres en lo obispado y para comprender cómo las CEBs ganaron sentido en la vida de cada una de ellas desde la perspectiva de la Historia de la Mujer. Durante la investigación, se notó que los sujetos principales de las CEBs, como también había demostrado Eder Sader (1988), eran y siguen siendo mujeres, que a menudo permanecen invisibles. La historia oral les permitió hablar sobre sus trayectorias y el papel de la Iglesia en la vida de las comunidades donde viven, además de su propia identidad como creyentes influenciado por la Teología de la Liberación, muy fuerte en América Latina. A través de las entrevistas fue posible analizar algunos aspectos señalados por Maria Aparecida, Helena Maria y Maria Lucely, que se explorarán a lo largo del artículo, como el tema de género dentro de la Iglesia, la importancia que otorgan a la cultura popular en sus acciones y la relación entre la memoria individual y colectiva.

Palabras clave CEBs - Mujeres - Historia oral - Memoria - Cultura popular.

$2 \cdot$ ano XII, n. I7, 202I • ISSN 2179-5487 
Se dou pão aos pobres, todos me chamam de santo.

Se mostro porque os pobres não têm pão, me chamam de comunista e subversivo.

(Dom Hélder Câmara)

\section{Introdução}

pós a realização do Concílio Vaticano II (1962-1965), observou-se na Igreja
Católica latino-americana maior movimentação para o sentido social da
evangelização, seguindo as propostas conciliares. Isso quer dizer que uma ênfase foi dada na perspectiva de atuação da Igreja Católica junto às camadas sociais pobres da periferia. Além disso, buscou-se maximizar a participação de leigos e leigas nos assuntos religiosos, promovendo engajamento pastoral e abertura para o diálogo, incentivando a presença da população nas questões relativas à política e fomentando a consciência de que a ação coletiva podia colaborar com a transformação de uma sociedade injusta e desigual.

O processo de renovação eclesial desencadeado pelo Concílio Vaticano II e, sobretudo, pela conferência de Medellín tem uma importância social muito grande, na medida em que redefine a presença e atuação da Igreja na sociedade. Isso vale particularmente em relação ao continente latino-americano: seja pelo imaginário religioso que o caracteriza e pela importância da Igreja como força social; seja pelo impacto que a mudança de lugar social da Igreja produziu no continente.

Outro acontecimento que também possuiu enorme relevância para o contexto religioso e político da América Latina foi a Terceira Conferência realizada em Puebla (México) no ano de 1979. Os discursos dos participantes estavam marcados pela necessidade de encontrar-se com a realidade de angústia vivida pelo povo latinoamericano, propondo, dessa forma, ações que pudessem combater as desigualdades e marginalizações:

Logo depois o presidente do CELAM [Conselho Episcopal Latinoamericano], cardeal Aloísio Lorscheider, colocou a assembleia diante de grandes pistas de trabalho, lembrando o grito de esperança e de angústia do povo latino-americano, que "pede uma resposta profética". E sugeria que "o mais urgente é a defesa ou a proclamação da dignidade da pessoa humana, a proclamação dos direitos fundamentais da América Latina à luz de Jesus Cristo". ${ }^{2}$

I JÚNIOR, Francisco de Aquino. “รo anos de Medellín - 5 anos de Francisco: perspectivas teológico-pastorais”. In: Perspectiva Teológica, v. 50, n. I, 20I8, p. 45.

2 SOUZA, Luiz Alberto Gómez de. “A caminhada de Medellín a Puebla”. In: Perspectiva Teológica, v. 3I, 1999, p. 228. 


\section{REVISTA ANGELUS NOVUS}

Tais conferências, especificamente, foram evocadas neste artigo porque serviram de base teórica e prática (por meio dos encaminhamentos finais) para a criação, o desenvolvimento e o incentivo das Comunidades Eclesiais de Base (CEBs), um modelo de organização eclesial que teria como referência pastoral uma rede articulada de comunidades: "À luz de Medellín, as experiências pastorais renovadas explodem por todo o continente e se desenvolve o enorme potencial das Comunidades Eclesiais de Base”. ${ }^{3}$ Além disso, conforme trata o documento de Puebla, as CEBs apresentaram-se como a reafirmação do eixo central de "opção preferencial pelos pobres”:

Os pobres não são apenas objeto de atenção preferencial; são também sujeitos da evangelização: "o compromisso com os pobres e oprimidos e o surgimento das Comunidades Eclesiais de Base ajudaram a Igreja a descobrir o potencial evangelizador dos pobres". ${ }^{4}$

No que se refere ao Brasil, o surgimento e desenvolvimento das CEBs ocorreram no contexto da Ditadura Militar iniciada em 1964. Segundo Frei Betto, as primeiras organizações das CEBs apareceram no início da década de 1960 na arquidiocese de Natal ou em Volta Redonda.5 Essa década foi marcada pela organização e estruturação das comunidades no território brasileiro. Por sua vez, a partir de 1970, percebe-se uma maior atuação e novas articulações das CEBs. Foi nessa década que aconteceram os primeiros Encontros Intereclesiais, ou seja, encontros realizados em âmbito nacional, que reuniam as lideranças e outros(as) participantes de diversas localidades do país e em que se discutiam questóes que norteavam o tema central do encontro.

O primeiro Encontro Intereclesial de CEBs acontece em Vitória, no Espírito Santo, em 1975, com o tema Uma Igreja que nasce do povo pelo Espirito de Deus (...). Em seguida ocorre novamente em Vitória, no Espírito Santo, o segundo Encontro Intereclesial de CEBs com o tema Igreja, Povo que caminha, em 1976. Ainda na década de 70, ocorre o Encontro Igreja, Povo que se liberta, em João Pessoa, na Paraíba, em $1978 .{ }^{6}$

Entende-se que o posicionamento assumido por uma parte da Igreja Católica como foi o caso de alguns bispos e padres - nos anos posteriores ao golpe de 1964, a saber, denúncias de crimes e censura e articulação junto aos perseguidos pela ditadura, assim como a solidariedade ao pobre, ao trabalhador e ao oprimido, foi fundamental

3 SOUZA, Luiz Alberto Gómez de. “A caminhada de Medellín a Puebla”. In: Perspectiva Teológica, v. 31, 1999, p. 226.

4 Ibid., p. 229.

5 BETTO, Frei. O que é Comunidade Eclesial de Base. Coleção Primeiros Passos. Editora Brasiliense: São Paulo, I981, p. I6.

6 MACHADO, Odilon Kieling. As CEBs no Rio Grande do Sul: o caso do bairro Mathias Velho - município de Canoas (1975-1988). 224 f. Dissertação (Mestrado em História) - Universidade Federal de Santa Maria, Santa Maria, 20I2. p. 68-69.

$4 \cdot$ ano XII, n. I7, 202I • ISSN 2179-5487 
para a organização de resistências. Conforme argumenta Eder Sader, as transformações vivenciadas pela Igreja Católica no final da década de 1960 e início de 1970 estiveram relacionadas com a própria repressão sofrida por membros religiosos, quando das contestações ao regime vigente: ${ }^{7}$

As transformações ocorridas então na Igreja não podem ser subestimadas. De um lado, a formação das comissões pastorais e a das comunidades de base não devem ser vistas como simples sucedâneos de organização anteriores que incorporavam leigos e dirigiam suas ações para a vida "profana” (...). De outro lado, as críticas feitas à organização social não se limitavam a questões secundárias, mas denunciavam os próprios fundamentos do sistema. ${ }^{8}$

Nessa perspectiva, a pesquisa buscou compreender os processos de desenvolvimento das CEBs na Diocese da Campanha, ${ }^{9}$ sul de Minas Gerais, por meio de um recorte de gênero: as narrativas e memórias de mulheres. A investigação mostrou que as $\mathrm{CEBs}$ na diocese surgiram tardiamente, se comparadas ao âmbito nacional. Os primeiros trabalhos realizados na região são da década de 1980, desenvolvidos por padres, religiosas e sob a coordenação diocesana de mulheres, estas últimas entendidas como sujeitos que tiveram papel fundamental, porém nem sempre conhecido e reconhecido por uma história majoritariamente masculina.

Conforme argumenta Michelle Perrot, ao se referir ao registro da História, durante muito tempo houve certo silêncio e invisibilidade quando se tratava da história das mulheres, e as razões para isso eram diversas. "Em primeiro lugar, porque as mulheres são menos vistas no espaço público, o único que, por muito tempo, merecia interesse e relato". Além disso, a autora também menciona que é possível perceber "o silêncio das fontes. As mulheres deixam poucos vestígios diretos, escritos ou materiais. Seu acesso à escrita foi tardio". ${ }^{\text {. }}$

Ademais, a historiografia tradicional colocava em segundo plano a história de determinados setores da sociedade. Privilegiando-se a análise dos chamados "grandes feitos”, dos eventos políticos de maior expressividade e dos personagens históricos de

7 Um dos casos foi o sequestro e a morte de um auxiliar de Dom Hélder Câmara em 1969. As marcas de crueldade foram tantas que seu corpo foi deixado exposto pelos assassinos. (SADER, Eder. Quando novos personagens entraram em cena: experiências, falas e lutas dos trabalhadores da grande São Paulo, 1970-80. Rio de Janeiro: Paz e Terra, 1988, p. I5I).

8 SADER, Eder. Quando novos personagens entraram em cena: experiências, falas e lutas dos trabalhadores da grande São Paulo, 1970-1980. Rio de Janeiro: Paz e Terra, 1988, p. I5I-I52.

9 Uma diocese (ou bispado) diz respeito a uma divisão territorial estabelecida pelo Papa para delimitar a área de atuação de um Bispo. Cada diocese possui um conjunto de paróquias que, por sua vez, são espaços delimitados de atuação de um ou mais padres. A escolha pela Diocese da Campanha parte de um interesse pessoal no conhecimento e entendimento sobre o desenvolvimento das CEBs dentro de um bispado do sul de Minas Gerais que foi lugar de várias experiências religiosas vivenciadas pela pesquisadora.

Io PERROT, Michelle. Minha história das mulberes. Tradução: Angela M. S. Corrêa. São Paulo: Contexto, 2007, p. 17 . 


\section{REVISTA ANGELUS NOVUS}

setores dominantes, sobretudo das áreas da política e da economia, outros sujeitos foram mantidos no anonimato. Segundo Losandro Antonio Tedeschi, as mulheres são um desses segmentos que, por muito tempo, não ocupou espaço na cultura histórica marcadamente androcêntrica e patriarcal:

Dessa maneira, os setores marginalizados como o feminino foram por muito tempo participantes ativos da história, mas submergiram muitas vezes no anonimato, apresentados de forma intencional, como aquele grupo anônimo e sem consciência histórica, cuja dinâmica e evolução interna careciam por completo de valor para os historiadores "tradicionais"."

Além deste trabalho fazer a opção pela história das mulheres, por entendê-la como importante, mas marginalizada, outro ponto também foi relevante na definição do recorte. Ao buscar possíveis indivíduos para serem entrevistados, percebeu-se que a maioria se tratava de mulheres, com ricas experiências vivenciadas nas CEBs. Por isso, concordando com o argumento de Maria das Dores Machado e Cecília Mariz, não se pode negar que, para entender a dinâmica dos movimentos religiosos, é preciso compreender o papel que as mulheres desempenham neles e o significado que eles possuem para elas. ${ }^{12}$

No que diz respeito à metodologia empregada no trabalho, com os procedimentos da história oral, foi possível dar ouvidos às narrativas das mulheres e compreender elementos referentes ao desenvolvimento das CEBs na diocese que não estão documentados em fontes escritas. Segundo Alessandro Portelli, a fonte oral é carregada de significados, tanto que "a primeira coisa que torna a história oral diferente (...) é aquela que nos conta menos sobre eventos que sobre significados”. ${ }^{13}$ Nesse sentido, é importante destacar que adentrar o campo da memória contribui para a percepção de significados por parte do historiador; afinal, a memória não é apenas "um depositário passivo de fatos, mas também um processo ativo de criação de significações”. ${ }^{14}$ Por meio das entrevistas foi possível notar como a atribuição de sentidos estava atrelada à própria constituição da subjetividade das mulheres e fazia parte de uma rede de memória coletiva, ou seja, vários sentimentos eram compartilhados e diversas referências eram evocadas, constituindo a identidade dos membros das CEBs, em especial a feminina.

II TEDESCHI, Losandro Antonio. Alguns apontamentos sobre história oral, gênero e história das mulberes. Dourados-MS: UFGD, 2014, p. 24.

I2 MACHADO, Maria das Dores C.; MARIZ, Cecília L. "Mulheres e práticas religiosas nas classes populares: uma comparação entre as igrejas pentecostais, as CEBs e os grupos carismáticos”. In: Revista Brasileira de Ciências Sociais, n. 34, São Paulo, 1997, p. 71. PORTELLI, Alessandro. “O que faz a história oral diferente”. In: Projeto História, I4, São Paulo, 1997, p. 31.

I4 Ibid., p. 33 .

$6 \cdot$ ano XII, n. I7, 202I $\bullet$ ISSN 2179-5487 
Ademais, conforme argumenta Robert Frank, a fonte oral possui duas particularidades fundamentais ao trabalho historiográfico. Em primeiro lugar, o autor evoca Jacques Ozouf para salientar que a narrativa oral é "uma fonte provocada", ou seja, "quando o historiador (...) interroga a testemunha, ele mesmo constrói a fonte, e seu usuário é ao mesmo tempo a seu modo o produtor”. Em segundo lugar, "a fonte oral é privilégio do historiador do presente”, isso quer dizer, segundo Philippe Joutard, citado por Frank, que é possível haver um "laço carnal” entre o historiador e o entrevistado. ${ }^{\text {Is }}$ Dessa maneira, as narrativas permitidas pela História Oral também contribuíram para a construção de fontes orais a respeito das Comunidades Eclesiais de Base da Diocese da Campanha de Minas Gerais.

Por fim, é importante considerar que a "história não é somente o estudo do passado, ela também pode ser, com um menor recuo e métodos particulares, o estudo do presente". ${ }^{16}$ Também inserida na História do Tempo Presente, pelo motivo de uma das experiências referir-se à década passada e à construção da memória ser mediada pelo presente, a investigação possibilitou a "contemporaneidade intrínseca" entre a pesquisadora e as colaboradoras. ${ }^{17}$

A pesquisa contou com a colaboração de três mulheres de diferentes localidades $\mathrm{da}$ diocese. A primeira entrevistada foi Maria Aparecida Carvalho (Cida) da cidade de Pedralva (MG). Cida foi coordenadora diocesana das CEBs entre os anos de 2002 e 2015, aproximadamente. A segunda entrevistada foi Helena Maria Bressani, da cidade de Três Pontas (MG). Helena começou os trabalhos com as CEBs em 1987, por meio de um encontro ao qual foi convidada a participar. E, por último, a terceira entrevistada foi Maria Lucely de Souza Ramos da cidade de Varginha (MG). Lucely começou a atuar nas CEBs diocesana em 1995. Apenas Helena não possuía trajetória ligada à Igreja até conhecer as CEBs, portanto, as Comunidades Eclesiais de Base foram a porta de entrada para a participação dela nos assuntos relacionados à Igreja Católica. As três colaboradoras vivenciaram momentos diferenciados quanto à participação - em décadas e contextos políticos diversos - mas cada narrativa é entendida aqui como Questôes para a história do presente. Tradução: Ilka Stern Cohen. São Paulo: EDUSC, 1999, p. 107.

I6 CHAUVEAU, A.; TÉTARD, Ph. (orgs.). Questôes para a bistória do presente. Tradução: Ilka Stern Cohen. São Paulo: EDUSC, 1999. p. I5.

I7 De acordo com o Manual de História Oral, de José Carlos Sebe B. Meihy, o termo colaborador deve substituir o de depoente ou informante, pois o entrevistado é muito mais que um fornecedor de informações, mais que um objeto de pesquisa. O diálogo que se estabelece entre ele e o entrevistador faz parte do processo de comprometimento com a publicização de uma história de vida, pressupondo intervenções de ambas as partes e a responsabilidade ética com a pesquisa (MEIHY, José C. S. B. Manual de História Oral. São Paulo: Melhoramentos, 2007, p. 124-I25). 


\section{REVISTA ANGELUS NOVUS}

representativa de outras experiências semelhantes, uma vez que a voz delas não é unívoca, mas portadora de muitas vozes femininas e religiosas.

Com as entrevistas foi possível observar a permanência e a riqueza das experiências vivenciadas por essas mulheres em uma diocese que apresentava em momentos diferentes, e ainda apresenta, um caráter bastante conservador, sobretudo pela posição assumida pelos bispos. Nesse sentido, várias questões foram levantadas e poderiam ser exploradas ao longo das narrativas. ${ }^{18}$ No entanto, apenas algumas foram selecionadas para compor este artigo, dada a limitação que se apresenta para tal trabalho. Os pontos nos quais a análise concentrou-se dizem respeito à cultura popular, à questão de gênero e à memória coletiva, relacionadas às CEBs. Esses aspectos foram analisados com base nas narrativas das mulheres e em bibliografias que versam sobre as temáticas.

\section{Cultura popular: "um jeito normal de ser igreja”}

O conceito de cultura popular não é algo fácil de ser definido, pois, conforme argumenta Marilena Chauí, "trata-se de saber quem, na sociedade, designa uma parte da população como 'povo' e de que critérios lança mão para determinar o que é e o que não é 'popular'”. ${ }^{9}$ Dessa forma, pode-se dizer que existe mesmo uma disputa em torno do conceito de cultura, sobretudo quando relacionado à questão de classe. Entretanto, partindo-se de uma definição mais ampla, a cultura seria o campo das formas simbólicas, ou seja, a religião, a linguagem, as artes, entre outras. Nas "relações com a História, a Cultura se torna o conjunto articulado dos modos de vida de uma sociedade determinada (...)”, ${ }^{20}$ ou seja, diz respeito também aos hábitos, costumes, festividades e crenças de um povo.

Voltando-se para uma conceituação mais restrita, a cultura "tende a identificar-se com a posse de conhecimentos, habilidade e gostos específicos, com privilégios de classe, e leva à distinção entre cultos e incultos, de onde partirá a diferença entre cultura letrada (...) e popular”. ${ }^{21}$ Nessa perspectiva, segundo Chauí, o popular pode estar inserido no

Temas que merecem pesquisa atenta estão relacionados aos padres, ex-assessores das CEBs, que se afastaram do ministério sacerdotal, procurando compreender a hierarquia e limites de atuação na Igreja; os símbolos e eventos, como as romarias do trabalhador e o Encontro Mineiro, que têm forte presença na vida das CEBs, assim como a grande quantidade de material das paróquias e as fotografias apresentadas pelas entrevistadas. Pela extensão restrita deste artigo, não foi possível desenvolvê-los, pretendendo-se fazer isso em futuras pesquisas.

CHAUI, Marilena. Conformismo e resistência. São Paulo: Brasiliense, 1996, p. Io.

$2 \mathrm{I}$ Ibid., p. I4.

$8 \cdot$ ano XII, n. I7, 202I $\bullet$ ISSN 2179-5487 
campo do regional, como guardião da tradição, possuindo uma lógica, práticas, representações e formas de consciência que lhe são próprias.

Entretanto, conforme discorre Martha Abreu, a expressão “cultura popular” não é algo engessado ou fixo, pois é necessário observar as mudanças ocorridas ao longo do tempo histórico, assim como as interações estabelecidas entre os sujeitos sociais:

(...) cultura popular não é um conceito passível de definição simples ou a priori. Cultura popular não é um conjunto fixo de práticas, objetos ou textos, nem um conceito definido aplicável a qualquer período histórico. Cultura popular não se conceitua, enfrenta-se. ${ }^{22}$

Sendo assim, esteve bastante presente nas narrativas a valorização que as Comunidades Eclesiais de Base davam para os aspectos culturais que dizem respeito à religiosidade do povo que dela participa e como suas práticas são politicamente importantes. Um dos destaques nos três discursos foi a realização da Romaria do Trabalhador. Trata-se do evento mais expressivo promovido pelas CEBs da Diocese da Campanha (MG). Acontece no primeiro domingo do mês de maio, sendo realizado, a cada ano, em uma cidade diferente com uma temática específica. ${ }^{23}$ Todas as cidades que possuem trabalhos de CEBs são convidadas a participarem, também diversos grupos culturais - como o Grupo Afro de Três Pontas (MG), congadas, e folia de reis movimento social - como o Movimento dos Trabalhadores e Trabalhadoras Sem Terra (MST) - e grupos indígenas, como foi o caso dos Krenak, citado por Cida Carvalho: " $\mathrm{E}$ nós trouxemos, pra Pedralva, indígenas, aqui de Caldas (...), todas as romarias vinha o pessoal do MST". ${ }^{24}$

A dinâmica do encontro diz respeito, basicamente, a uma caminhada realizada na cidade que sedia o evento. Cada parada da caminhada é destinada à reflexão de um aspecto da metodologia das CEBs, ou seja, na primeira parada reflete-se sobre o "ver", na segunda sobre o "julgar" e na terceira sobre o "agir", com base no tema proposto para a romaria. Ao final da caminhada é realizada uma celebração de encerramento. Em todos os momentos as apresentações culturais estão presentes. Além disso, a romaria é organizada a partir do ideal comunitário, quer dizer, o lanche da manhã é comunitário e, para o almoço, os alimentos são doados pela comunidade, como enfatizou Helena:

Aí veio a Pastoral da Criança, (...) a Pastoral de Conjunto, grupos culturais - (...) o Grupo Afro, antigamente chamava Grupo Afro - aí eles participavam, folia de reis, congado de outras paróquias, de Machado, vinha gente até da microrregião; diocese de Pouso Alegre,

22 ABREU, Martha. "Cultura popular, um conceito e várias histórias”. In: ABREU, Martha; SOIHET, Rachel. Ensino de História, Conceitos, Temáticas e Metodologias. Rio de Janeiro: Casa da Palavra, 2003, s/p.

23 A primeira romaria aconteceu em 1990.

24 Entrevista concedida por Cida Carvalho para a entrevistadora em 23/07/2019. 


\section{REVISTA ANGELUS NOVUS}

de Guaxupé (...) As romarias (...) [tinham] muitos símbolos, celebrações muito bonitas, o pessoal investia nas dinâmicas, tinha dramatização de evangelho (...) Para cada intervalo tinha uma apresentação cultural. ${ }^{25}$

Também foi mencionada, em todas as entrevistas, que a realização de determinados eventos pelas CEBs, sobretudo a Romaria do Trabalhador, encontrava diferentes modos de resistências por parte daqueles que possuíam algum tipo de preconceito ou que se tratava de pessoas com alto poder aquisitivo. Sob essa linha, reforça-se o argumento de que a cultura está no palco de disputas das classes sociais existentes na sociedade brasileira, e de que "as classes ditas 'subalternas' de fato o são e carregam os estigmas da suspeita, da culpa e da incriminação permanentes”. ${ }^{26} \mathrm{~A}$ colaboradora Cida demonstra esta percepção ao lembrar das vezes em que membros do MST e povos indígenas iam participar das romarias a convite das CEBs:

Então, quando ficaram sabendo que nós íamos trazer o pessoal do MST, foi uma guerra na cidade! (...) É só falar "ah, romaria do trabalhador”, o povo já falava: "ah, é aquele bando de comunista”, "ah, eles vão trazer o MST” (...) Em Carmo de Minas também nós tivemos muita resistência dos grandes fazendeiros, porque eles iam fazer uma denúncia, o MST e o sindicato dos trabalhadores rurais iam fazer uma denúncia por causa, assim, de algum trabalho escravo que tinha nas colheitas de café. Então foi aquele ... quase que não aconteceu a romaria de novo. Teve lugar de acontecer de polícia tá sondando: "ah, vem MST, vem índio, vem trabalhador rural” ... Então, todo mundo achava que a gente era bandido!! Alguns acham até hoje! Mas esse tipo de resistência era comum. ${ }^{27}$

Outra questão colocada pelas entrevistadas diz respeito à perseguição sofrida por alguns membros das Comunidades Eclesiais de Base por causa de posturas adotadas frente a determinados setores conservadores das cidades em questão. Em umas das entrevistas ficou evidente que a proposta das CEBs e a máxima da "opção preferencial pelos pobres" incomodavam e geravam diversos conflitos, inclusive no seio familiar:

Enfrentamos muitos desafios, por quê? Porque, de uma certa forma, o trabalho de CEBs fala dessa questão de justiça social, e a cidade é conservadora. Então, na época, o [padre] Zé Jorge foi muito perseguido aqui; os fazendeiros fazendo pressão... Aí a gente reunia aqui, firmava junto com as demais comunidades pra não tirá-lo daqui, sabe (...) Inclusive, tinha aquela música das CEBs, eu não sei se você conhece, diz assim: "irá chegar um novo dia, e nesse dia, (...) o índio, o negro, o branco e o mulato vão comer no mesmo prato” ... Nossa! Foi um problema, sabe. Assim, de fazendeiro, de vir aqui em casa, de fazer pressão, de falar que era empresário que tava falando, que tava sendo explorado, sabe ... Então, houve

\footnotetext{
25 Entrevista concedida por Helena para a entrevistadora em 31/07/2019.

26 CHAUI, Marilena. Conformismo e resistência. São Paulo: Brasiliense, 1996, p. 57

27

Entrevista concedida por Cida Carvalho para a entrevistadora em 23/07/2019.
}

Io $\bullet$ ano XII, n. I7, 202I • ISSN 2179-5487 
muito conflito! Na época, meu pai tinha uma cabeça diferente, ficou sem conversar também. ${ }^{28}$

As CEBs, em grande medida, apresentavam-se como alternativa ao catolicismo oficial, ordenado, hierárquico e, muitas vezes, deslocado das diferentes realidades culturais do povo brasileiro. Conforme argumenta Maria Cecilia Domezi, o novo tipo de catolicismo expresso pelas CEBs - "catolicismo internalizado popular de libertação" - considera as realidades específicas dos lugares onde as comunidades estão presentes. Nesse sentido, entre outros aspectos, reflete sobre as lutas sociais do povo, a necessidade de recursos materiais e espirituais para os mais pobres e busca uma renovação da sociedade, para torná-la mais justa e solidária. ${ }^{29}$ É a partir dessa perspectiva que a própria espiritualidade - manifestada nas mais variadas formas de oração, por exemplo - ganha novos sentidos, deixando de ser apenas a "reza” para tornar-se também uma prática social que busca a transformação.

É moderna a afirmação insistente dos membros de CEBs de que “não basta só rezar", mas é preciso engajar-se na práxis transformadora da sociedade. Rompe-se consciente e deliberadamente com a atitude de rezar ou orar esperando que toda ação venha de Deus e dos santos; a convicção é de que "Deus age através de nós". ${ }^{30}$

Além disso, as CEBs expõem outra face da Igreja Católica e mesmo da sociedade brasileira no geral, que ainda é autoritária e conservadora. Segundo Chauí, “a organização das comunidades eclesiais de base e das sociedades amigos de bairro (...) são práticas que desordenam a ordem e expõem 'qual seria a nossa formação moral e cívica'” ${ }^{31}$ No entanto, não se pode negar a contribuição que as Comunidades Eclesiais de Base já ofereceram para a Igreja Católica no Brasil, sobretudo no amparo aos perseguidos pela Ditadura Militar. ${ }^{22}$ Uma das entrevistadas falou sobre isso:

Eu lembro que aqui no Sant'Ana houve uma resistência muito grande na época (...) Mas, foi uma mudança, inclusive de bispo, de padre, sabe. O bispo chegou, não sei se foi o Dom Diamantino na época, não me lembro, mas ele chegou e mudou o padre. Mandaram outro padre completamente ao avesso da CEBs, entendeu? Então, aconteceu isso demais da conta! Eu acho assim, eu sinto que a Igreja, enquanto precisou das CEBs, de uma base pra,

28 Entrevista concedida por Helena para a entrevistadora em 31/o7/2019.

29 DOMEZI, Maria Cecilia. A DEVOÇÃO NAS CEBs: Entre o Catolicismo Tradicional Popular e a Teologia da Libertação. 329 f. Tese (Doutorado em Ciências da Religião) - Pontifícia Universidade Católica de São Paulo, São Paulo, 2006, p. 6r.

$30 \quad$ Ibid., p. 69.

3I CHAUI, Marilena. Conformismo e resistência. São Paulo: Brasiliense, 1996, p. 178.

32 Ver mais: MACHADO, Odilon Kieling. As CEBs no Rio Grande do Sul: o caso do bairro Mathias Velho município de Canoas (1975-1988). 224 f. Dissertação (Mestrado em História) - Universidade Federal de Santa Maria, Santa Maria (RS), 2012. 


\section{REVISTA ANGELUS NOVUS}

naquele começo do regime militar, pra fazer com que crescesse (...) aí aproveitaram. Depois, veio a Renovação Carismática ... a Renovação Carismática é o avesso das CEBs. Aí nessa época teve realmente muita resistência e é onde que aconteceram essas substituições. Não foi só aqui na paróquia, em vários lugares teve essas restrições pra desmantelar mesmo o trabalho, né? Aqui foi um desmantelamento!33

Nesse sentido, a narrativa de Lucely permitiu a reflexão sobre como, em alguns momentos, a participação nas Comunidades Eclesiais de Base apresentou-se como um caminho bastante árduo para a vivência da religiosidade cristã católica na perspectiva dos trabalhos propostos pelas CEBs junto à sociedade e à Igreja. As principais dificuldades encontradas, como destacou Lucely, foram desencadeadas pela resistência e falta de apoio da instituição, representada, nesse caso, pelo bispo.

Partindo da ideia de que as CEBs representam um "jeito normal de ser Igreja”, conforme narrou Cida Carvalho, é possível perceber que os trabalhos desenvolvidos e a própria metodologia adotada têm como foco a promoção humana - especialmente dos menos favorecidos -, a justiça e as consciências individual e social. A discussão a seguir propõe-se à reflexão sobre a tomada de consciência individual quanto à própria vida e à atribuição de sentido a ela, a partir da vivência nas CEBs.

\section{Questão de gênero: “as CEBs são a menina dos meus olhos; ali eu encontrei a minha identidade."}

Outro ponto a ser abordado e bastante presente nas narrativas femininas foi a questão da participação de mulheres nos trabalhos das CEBs e na estrutura eclesial mais ampla da Igreja Católica. Também foi mencionado o significado que o movimento trouxe para a vida delas e de como isso contribuiu para a própria constituição da subjetividade de cada uma. No Brasil, uma das primeiras discussões sobre a atuação das Comunidades Eclesiais de Base nos movimentos históricos é o trabalho de Eder Sader: Quando novos personagens entraram em cena: experiências, falas e lutas dos trabalhadores da Grande São Paulo (1970-80). Apesar de se tratar de uma temporalidade e de um espaço diferentes do que esta pesquisa se propôs a fazer, é importante mencionar que Sader já apontava as CEBs como parte de um contexto de advento de novos sujeitos nos processos de transformação da realidade social, imposta de maneira autoritária. Nesse sentido, a criação dos “clubes de mães” na periferia sul de São Paulo já estava inserida na ideia da atuação das mulheres em ambientes extradomésticos e na tomada de consciência do papel feminino em posições de liderança. Dessa maneira, “os 
objetivos fundamentais do movimento - o valor da mulher, sua participação como cidadã, a importância de cada uma lutar por seus direitos - [estavam] vinculados a uma interpretação do cristianismo à luz dos textos de Medellín e da teologia da libertação”. ${ }^{34}$

Conforme argumenta Tedeschi, a discussão sobre gênero precisa levar em conta que ele é um "operador de diferenças", ou seja, as convivências estabelecidas em sociedade e as experiências, tanto individuais quanto coletivas, organizam-se a partir das relações de gênero, ou ao menos tangenciam-nas. Levando isso em conta, foi possível perceber que as mulheres entrevistadas possuem consciência de que suas experiências estiveram inseridas em um contexto de religiosidade amplo e não apenas naquele em que os papeis sexuais são definidos. Como afirma o autor, as lembranças femininas são marcadas pelas diferenciações de gênero, mas "está muito distante de afirmar uma especificidade da memória feminina, ancorada na biologia ou, no âmbito do social, nos papéis sexuais”. ${ }^{35}$

Analisando alguns processos desenvolvidos pelas Comunidades Eclesiais de Base ao longo dos anos, a metodologia adotada (ver-julgar-agir), o eixo norteador dos trabalhos (“opção preferencial pelos pobres”) e uma bibliografia especializada, é possível perceber que a discussão sobre as relações de gênero não se apresenta como um ponto central nas CEBs. "O objetivo primeiro não é a transformação da cultura patriarcal. Sua missão é religiosa e, em segundo lugar, política. Assim, não é de estranhar que a questão de gênero tenha permanecido subordinada à questão de classe".$^{36}$ Nas romarias realizadas, por exemplo, os temas foram bastante diversificados questão da terra, justiça, juventude, trabalho, etc. -, mas nunca houve uma romaria em que a temática se propusesse a discutir a questão da mulher, menos ainda, as relações de gênero. Desse modo, observou-se nas narrativas que o assunto sobre a questão de gênero estava relacionado a uma postura mais pessoal e/ou feminina do que propriamente inerente ao movimento. A análise que as entrevistadas fazem mostra as marcas do tempo presente, já atravessado por questóes mais claras sobre o papel das mulheres na sociedade e nas posições de mando. São memórias atualizadas por questões relacionadas à postura conservadora da Igreja, que talvez já existissem no passado, mas que se tornam mais vivas hoje nas colocações das entrevistadas:

34 SADER, Eder. Quando novos personagens entraram em cena: experiências, falas e lutas dos trabalhadores da grande São Paulo, 1970-1980. Rio de Janeiro: Paz e Terra, 1988, p. 210.

35 TEDESCHI, Losandro Antonio. Alguns apontamentos sobre história oral, gênero e história das mulheres. Dourados-MS: UFGD, 2014, p. 19.

36 COUTO, Márcia Thereza. "Na trilha do gênero: pentecostalismo e CEBs". In: Estudos feministas, n. ro, Santa Catarina, 2002, p. $36 \mathrm{I}$. 


\section{REVISTA ANGELUS NOVUS}

Essa questão do gênero, a gente costumava usar a expressão "nós mulheres servimos na Igreja pra lavar toalha de altar, pra varrer chão, pra fazer limpeza, pra lavar túnica de padre", o resto ... pra isso a gente serve. Mas, pra assumir papéis, por exemplo, o diaconato feminino, não tem! $\mathrm{E}$ isso nós já debatemos em reuniões, em assembleias diocesanas, nunca nós tivemos voz!!! Tanto essa "demissão” nossa, da equipe ... coordenação era feminina! (...) Por que não ordenar mulheres? Existia, existia não, existe ainda uma luta né? Nas outras igrejas tem pastoras, (...) bispas. ${ }^{37}$

(...) Porque a Igreja ainda é muito conservadora, né?! Nossa Mãe! Eu, por exemplo, não aceito a Igreja não ter sacerdotisas; por que só sacerdote?! Diaconisas ... tinha que ter, só tem diáconos! Então ela precisa se abrir. ${ }^{38}$

Apesar de o debate sobre as relações de gênero não se constituir prioridade nas CEBs, não se pode negligenciar a importância de tal movimento para o contexto do mundo feminino. Em primeiro lugar, as CEBs possibilitaram o desenvolvimento de uma postura crítica e autônoma nas mulheres que, muitas vezes restritas ao ambiente do lar, descobriram novas possibilidades com a inserção em um espaço extradoméstico. Exemplos disso são as novas redefinições de visão de mundo que surgiram e a ocupação de posições de liderança dentro dos trabalhos realizados:

Ao valorizar a igualdade e a possibilidade de todos participarem das decisóes, ao enfatizar a ideia de que cada um possui direitos que podem e devem ser reivindicados, as CEBs ajudam as mulheres a desenvolver uma visão mais crítica como pobre e como mulher. ${ }^{39}$

Além disso, vale mencionar que as Comunidades Eclesiais de Base viveram um duplo movimento no que refere à questão da mulher e à participação na política. Duas das três mulheres entrevistadas já possuíam passagem pela política, ou, como elas disseram, já “eram politizadas”. Cida Carvalho já foi vereadora na cidade de Pedralva (MG), pelo Partido dos Trabalhadores (PT), entre os anos de 2000 e 2004; Helena já foi filiada ao PT e acredita que hoje "está mais para PDT [Partido Democrático Trabalhista]". Sendo assim, ambas encontraram nas CEBs um espaço em que se discutia a vida do povo à luz da fé, mas, que ao mesmo tempo, promovia engajamento e consciência política:

E quando aconteceu esse encontro das CEBs [em 1987], ali eu me identifiquei, porque eu já era assim, um pouco, mais ou menos, politizada. Não muito, tanto evangelizada, mas politizada; e as CEBs tratavam da questão social, então aquilo me atraiu..$^{\circ}$

37 Entrevista concedida por Cida Carvalho para a entrevistadora em 23/07/2019.

38 Entrevista concedida por Lucely para a entrevistadora em oI/o8/2019.

39 MACHADO, Maria das Dores C.; MARIZ, Cecília L. "Mulheres e práticas religiosas nas classes populares: uma comparação entre as igrejas pentecostais, as CEBs e os grupos carismáticos”. In: Revista Brasileira de Ciências Sociais, n. 34, São Paulo, 1997, p. 75. 
Em segundo lugar, conforme tratam Maria das Dores C. Machado e Cecília L. Mariz, "as CEBs inovaram ao motivar as mulheres para a política (...). Algumas não apenas participam nos movimentos sociais como se tornam liderança e até candidatas por partidos políticos". ${ }^{41}$ Posto isso, é preciso reconhecer o papel fundamental desempenhado pelas Comunidades Eclesiais de Base no tocante à politização das mulheres, ainda que, mais uma vez, esta não fosse a proposta principal do movimento.

Ademais, outro fator substancial dessa questão de gênero diz respeito aos significados produzidos pelas CEBs na vida das entrevistadas e na constituição da subjetividade de cada uma delas. Em uma das entrevistas, encontra-se a referência à valorização da mulher, mesmo com os limites da organização religiosa:

Eu vejo, nossa! É isso que me fez a valorização da mulher, sabe; minha, eu!! Eu tive a experiência de me sentir, realmente, valorizada, nessa introdução minha nas CEBs, porque foi com ela. E o padre Moacir é quem dava também esse aval pra mulher, né? Então, eu acho que isso aí é uma experiência que marca muito também, sabe. Muito marcante. ${ }^{42}$

Percebe-se, com isso, que a participação nos trabalhos de CEBs esteve intimamente relacionada com a questão da autoestima da mulher e do que isso significa para ela até os dias atuais. A busca de pertencimento a um grupo e o interesse em se viver a fé para além do ambiente doméstico também precisam ser considerados, conforme argumentam Machado e Mariz: "o motivo geralmente alegado para participar das CEBs relaciona-se (...) com a necessidade de participar de um grupo, de pertencer a uma unidade ou, também, de refletir sobre a fé ou de se aprofundar nela”. ${ }^{43}$

A questão sobre a constituição da identidade religiosa, comunitária e feminina, ou a reflexão sobre ela, conforme esteve presente nas narrativas, corroboram a ideia da importância do trabalho com a memória para a interpretação que as mulheres fazem de suas próprias vidas e suas vivências em diversos meios sociais. "Quando falamos de história das mulheres, referimo-nos a um processo de tomada de consciência de si mesmo. (...) Ao narrá-la (...) cria um processo de identidade a partir da experiência da própria vida e dos sujeitos que a cercam e convivem". ${ }^{44}$

Portanto, a pesquisa identificou que a questão de gênero nas Comunidades Eclesiais de Base da Diocese da Campanha (MG) está ligada a uma postura mais pessoal

4I MACHADO, Maria das Dores C.; MARIZ, Cecília L. "Mulheres e práticas religiosas nas classes populares: uma comparação entre as igrejas pentecostais, as CEBs e os grupos carismáticos”. In: Revista Brasileira de Ciências Sociais, n. 34, São Paulo, 1997, p. 74.

42 Entrevista concedida por Lucely para a entrevistadora em oI/o8/2019.

43 MACHADO; MARIZ, op. cit., p. 74.

44 TEDESCHI, Losandro Antonio. Alguns apontamentos sobre história oral, gênero e história das mulheres. Dourados-MS: UFGD, 2014, p. I4. 


\section{REVISTA ANGELUS NOVUS}

ou de um grupo de mulheres, uma vez que no âmbito institucional esse ponto não é debatido. Esse é um aspecto para futuras investigações e problematizações, tendo em vista que a coordenação dos trabalhos de CEBs no bispado fica a cargo de mulheres até hoje, mas quem responde por esses trabalhos no âmbito institucional da igreja trata-se de um homem, um padre, que é o assessor.

Apesar dessa noção bastante individual ou restrita a um grupo de mulheres sobre a participação feminina em funções religiosas específicas, as narrativas foram consideradas sob a perspectiva de uma memória coletiva, como afirma Tedeschi:

Quem narra, presencia o relato de suas vidas, e faz em uma dupla qualidade de indivíduos singulares e de sujeitos coletivos. Cada uma delas é única, mas no caminho da construção da sua subjetividade têm sofrido a influência familiar, social, cultural, socioeconômica do meio em que viveram ou vivem. Como sujeitos singulares, encarnam de maneira única e irrepetível valores, modas, costumes, normas, mitos de ordem familiar, grupal, social, que as incluem no que fazem dentro de um contexto social que não é estático, pelo contrário, está continuamente afetado por contradições, rivalidade e tensões de seus membros. ${ }^{45}$

Nesse sentido, como será abordado a seguir, as memórias das mulheres entrevistadas estão inseridas em um contexto amplo, e não apenas no sentido individual. Tendo em vista que várias referências externas vieram à tona no momento em que a narrativa se passava, é necessário considerar toda uma rede de falas e posturas que fazem parte da coletividade na qual tais mulheres exerceram e ainda exercem papéis importantes.

\section{Memória coletiva: "falar de CEBs é falar de maturidade, de conhecimento, de embasamento."}

A pesquisa em história oral pressupõe que a memória seja evocada no momento em que se narra as experiências. Sendo assim, os indivíduos buscam as lembranças de um passado recente, selecionam determinados aspectos e ordenam o modo como essas lembranças serão ditas ao longo da entrevista. Nessa perspectiva, trabalhar com a memória demanda do pesquisador uma atitude bastante respeitosa e compreensiva, visto que vários sentimentos podem ser despertados e o silêncio, o não-dito e o esquecimento também fazem parte da narrativa.

Apesar de a memória parecer algo subjetivo e próprio de cada colaborador, ela está permeada por um universo de referências que vêm à tona no momento da conversa. Por

45 TEDESCHI, Losandro Antonio. Alguns apontamentos sobre história oral, gênero e história das mulheres. Dourados-MS: UFGD, 2014, p. 35.

I6 • ano XII, n. 17, 202I • ISSN 2179-5487 
isso, comungando da reflexão de Michael Pollak e Maurice Halbwachs, a memória pode ser entendida como um fenômeno coletivo e construído:

A priori, a memória parece ser um fenômeno individual, algo relativamente íntimo, próprio da pessoa. Mas Maurice Halbwachs, nos anos 20-30, já havia sublinhado que a memória deve ser entendida também, ou sobretudo, como um fenômeno coletivo e social, ou seja, como um fenômeno construído coletivamente e submetido a flutuaçôes, transformações, mudanças constantes. ${ }^{46}$

Segundo Maria Paula Araújo e Myrian dos Santos, é preciso entender que os indivíduos estabelecem diversas relações sociais, tornando-se, assim, frutos das próprias interações que são organizadas. As construções coletivas permeiam a vida humana desde o nascimento até a morte, por isso, a memória não é algo restrito ao campo do individual, mas está inserida no universo da coletividade. “(...) Ainda que o indivíduo pense que sua memória é estritamente pessoal, (...) ela é coletiva, pois o indivíduo ainda que esteja só é o resultado das interações sociais. Ele vê o mundo através de construções coletivas como a linguagem". ${ }^{47}$ Nessa linha, quando da entrevista, é preciso considerar não apenas os acontecimentos vivenciados de forma pessoal, mas, sobretudo, os eventos vividos pela coletividade. Partindo desta concepção, é possível perceber que as experiências das mulheres entrevistadas possuem alguns pontos em comum, já que elas fazem parte de um contexto em que a memória é compartilhada. Dentre as práticas experienciadas por cada uma delas, questôes como a solidariedade, o cristianismo voltado para o popular e a própria ideia da participação feminina podem ser apontados como pontos convergentes.

Enquanto participante e atuante nas Comunidades Eclesiais de Base, Helena esteve presente no desenvolvimento dos setores missionários, as chamadas "pequenas comunidades", ${ }^{48}$ assumiu funções de secretariado e, posteriormente, passou a compor a coordenação diocesana das CEBs. Além disso, participou de diversos cursos de formação como, formação bíblica, história da Igreja e conjuntura política. Esteve ligada também à preparação de um encontro ecumênico na cidade de Três Pontas-MG e na organização de um debate político, na ocasião do ano eleitoral, em que o próprio povo fazia perguntas aos candidatos. Outra importante ação foi a criação de uma Tribuna 46 POLLAK, Michael. "Memória e identidade social”. In: Estudos Históricos, v. 5, n. Io, Rio de Janeiro, I992, p. 201.

47 ARAÚJO, Maria Paula Nascimento; SANTOS, Myrian Sepúlveda dos. "História, memória e esquecimento: implicações políticas”. In: Revista Crítica de Ciências Sociais, 79, 2007, p. 97.

48 Os setores missionários podem ser considerados os principais frutos das CEBs que ainda existem de forma bastante ativa na Diocese da Campanha (MG). Trata-se da reunião de pessoas da mesma rua, do mesmo bairro ou do mesmo "setor" para a reflexão de assuntos relacionados à vida do povo na Igreja e na sociedade, com base nos textos dos evangelhos presentes na bíblia. Cada paróquia organiza a dinâmica específica dos setores missionários, mas o material de reflexão é comum, sendo elaborado pela diocese. 


\section{REVISTA ANGELUS NOVUS}

Livre na Câmara Municipal, que se tratava do levantamento de problemas enfrentados pela população, os quais seriam levados à reunião ordinária dos vereadores. A organização de romarias, a criação de uma entidade que atendia crianças e famílias em situação mais vulnerável, a criação de associações de bairro e a atuação na Pastoral Catequética também foram ações que contaram, efetivamente, com a colaboração de Helena. ${ }^{49}$

Por sua vez, Lucely começou a se envolver com as CEBs através do padre Moacir que, segundo ela, “era um padre muito (...) evoluído, muito visionário e ele já sonhava com CEBs. Ele já tinha uma visão libertadora, de fazer com que as pessoas buscassem esse comprometimento de transformar sua realidade e ser o autor de si mesmo (...)". . $^{\circ}$ Ela atuou na Pastoral Vocacional, foi coordenadora do Conselho Pastoral Paroquial (CPP) e da Pastoral Catequética. Efetivamente com as práticas das CEBs, Lucely participou dos trabalhos de formação nas zonas rurais da cidade de Varginha-MG, conscientizando e organizando as comunidades; também articulou a realização das romarias do trabalhador, enquanto estava na coordenação diocesana das CEBs, e esteve presente em vários encontros realizados a níveis local e regional. Atualmente, ela participa de um Grupo de Apoio às Transformações Sociais, que segue a perspectiva de engajamento das comunidades no plano social..$^{\text {si }}$

Cida, por sua vez, atuou em diversos outros segmentos que não apenas os trabalhos de CEBs. Começou, na adolescência, atuando como catequista e participando de grupos de jovens na paróquia. Depois, quando do período em que estava na universidade, ajudou a fundar a Pastoral Universitária, integrando pessoas de diferentes cursos de graduação. Além disso, junto com uma amiga, rearticulou a Pastoral da Saúde na cidade de Pedralva-MG, que tinha como objetivo a promoção e a transformação da vida das pessoas. A pastoral encarregava-se de distribuir remédios no município e fazer campanhas de combate às verminoses através da aquisição de filtros. Tendo em vista a ideia de que somente a participação na Igreja sem a transformação de vidas seria algo incoerente, Cida denunciava a injustiça, a falta de saneamento básico, o desemprego, entre outros problemas que envolviam o povo. Além disso, quando organizou as romarias do trabalhador, mobilizou todas as comunidades para que pudessem ajudar, mesmo que fosse com o mínimo possível. Outra ação foi a visita realizada no acampamento e no assentamento do Movimento dos Trabalhadores e Trabalhadoras

\footnotetext{
49 Entrevista concedida por Helena para a entrevistadora em 31/07/2019.

50 Entrevista concedida por Lucely para a entrevistadora em oI/o8/2019.

SI Ibid.
}

I8 $\bullet$ ano XII, n. I7, 202I • ISSN 2179-5487 
Sem Terra (MST), em Campo do Meio-MG. Hoje em dia, Cida faz alguns trabalhos sociais de maneira individual. ${ }^{52}$

Analisando as narrativas das ações de cada uma das mulheres nas Comunidades Eclesiais de Base (e em outros trabalhos sociais) é possível perceber o quanto as lembranças fazem parte de um contexto coletivo, ou seja, foram experiências vividas, majoritariamente, em contato e em colaboração com outros indivíduos. Suas memórias demonstram, também, a consciência de mulheres que se reconhecem como sujeitos ativos de sua história e de uma história coletiva de resistência. Evidenciam a perspectiva de Eder Sader sobre "novos sujeitos" ocupando o espaço político - mesmo que sob o âmbito religioso. Foi bastante enfático nas entrevistas que a organização das romarias, especialmente, era feita sempre em conjunto, em que a opinião de todos era ouvida e discutida coletivamente, inclusive das mulheres. Dessa forma, segundo Tedeschi, reforça-se a noção já mencionada de que o individual e o coletivo estão em constante trânsito e, juntos, são parte importante na formação de consciência em relação às práticas vivenciadas:

A construção de lembranças envolve a utilização de códigos culturais compartilhados. Apesar de as memórias pessoais serem únicas e irrepetíveis, uma pessoa nunca recorda sozinha, sempre está imersa em uma ordem coletiva que a contém. Dizemos que as pessoas falam - cada vez - como sujeito individual e coletivo, então, quando criam e transmitem suas lembranças, o faz a partir dessa dupla condição. A lembrança coletiva pressupõe e se expressa somente a partir da recordação individual. Sem a presença de ambos fica impensável a formação da consciência e, portanto, da memória coletiva histórica. ${ }^{53}$

Conforme argumenta Halbwachs, "os fatos e as noções que temos mais facilidade em lembrar são do domínio comum, pelo menos para um ou alguns meios". ${ }^{44}$ Corroborando essa afirmação, em vários momentos se notou que a busca por referências faziam as entrevistadas voltarem aos eventos vivenciados em conjunto, como os encontros ou as romarias:

Ah, os intereclesiais. Nossa, os intereclesiais são magníficos, menina! É coisa, assim, que te mexe tanto. É emocional, físico, espiritual ... uma coisa tão encarnada. O de Ilhéus nós tivemos lá a participação dos índios ... A gente participou com eles da roda do fogo ... Que coisa maravilhosa que era você ficar com eles ali, fazendo aquela experiência. Teve a celebração da Terra Sem Males que foi responsabilidade nossa. Então foi maravilhoso! (...) Organizarmos Dourados-MS: UFGD, 2014, p. 38. 


\section{REVISTA ANGELUS NOVUS}

aquela celebração da Terra Sem Males, sabe. Teve uma cruz muito grande que o pessoal trouxe, depois vela, os símbolos que a gente usou ... Nossa, foi lindo!ss

Além disso, a memória coletiva também pode estar relacionada ao sentimento e à constituição da própria identidade, pois tal aspecto aprimora-se por meios das relaçóes interpessoais estabelecidas nos grupos aos quais se pertence. "A construção da identidade é um fenômeno que se produz em referência aos outros, (...) aos critérios de aceitabilidade, de admissibilidade, de credibilidade, e que se faz por meio da negociação direta com outros"..$^{66}$

Dessa forma, por meio de uma das narrativas foi possível analisar que a participação nas CEBs teve fundamental importância, não apenas para a constituição da subjetividade, como já mencionado, mas também para o processo de reflexão sobre a identidade enquanto indivíduo e coletivo:

Aprendi muito também! Porque às vezes a gente é muito egoísta de ver nas pessoas... Essa questão da solidariedade. Ver o outro como se fosse eu! Isso aí eu aprendi; isso aí eu tenho muito aflorado em mim. Independente de qual que seja o problema. De respeitar a limitação do outro, de ter paciência, então isso eu aprendi. Tudo o que eu vou fazer, se for em termo de celebração, de envolver pessoas mais novas, pessoas mais velhas, de envolver crianças, ter paciência de explicar ... de dar um jeito de que todos possam participar, de correr atrás. Então, isso aí eu aprendi com as CEBs. ${ }^{57}$

A reflexão sobre o processo de constituição da subjetividade de cada uma das mulheres está relacionada à especificidade da abordagem da memória coletiva em uma perspectiva de gênero. Segundo o argumento de Tedeschi, esse desenvolvimento não se dá apenas pelos marcos de datas ou pelo quanto de conhecimento foi acumulado com as experiências. A memória "está formada por práticas culturais, tradicionais, valores, ritos, modos de relação, símbolos, crenças, determinados muitas vezes por representações do que é ser homem e mulher na história, definindo sua identidade"..$^{8}$

Uma questão que apareceu em duas entrevistas, e é importante de ser mencionada, diz respeito à visão que as entrevistadas têm das CEBs atualmente, já que elas não participam mais, ativamente, dos trabalhos. Uma das mulheres concebe as Comunidades hoje como parte integrante de outros movimentos e pastorais dentro da

\footnotetext{
55 Entrevista concedida por Lucely para a entrevistadora em oI/o8/2019.

${ }_{56}$ POLLAK, Michael. “Memória e identidade social”. In: Estudos Históricos, v. 5, n. Io, Rio de Janeiro, 1992, p. 204.

57 Entrevista concedida por Helena para a entrevistadora em 31/07/2019.

58 TEDESCHI, Losandro Antonio. Alguns apontamentos sobre história oral, gênero e história das mulheres. Dourados-MS: UFGD, 2014, p. 42.
}

$20 \cdot$ ano XII, n. I7, 2021 $・$ ISSN 2179-5487 
Igreja Católica, ou seja, não mais como um movimento com uma identidade própria, mas sim, integrado:

Depois as CEBs foram ficando integradas nesses trabalhos da Igreja; elas não foram mais uma coisa... Integraram a Pastoral Social, nos conselhos, nos CPPs [Conselhos Pastorais Paroquiais], nos CPCs [Conselhos Pastorais Comunitários] das comunidades, foi criando essa coordenação e esses próprios conselhos já vão gerindo as comunidades hoje (...) Porque as CEBs tiveram essa febre no começo, depois elas deram essa fracassada, não vamos dizer fracassada, mas deu essa integrada na Igreja, que ficou esse trabalho mais a nível social, essa distribuição das tarefas, das formações, deu essa estrutura. ${ }^{59}$

A entrevistada Helena concebe as CEBs na atualidade com uma nova estrutura, ou seja, as pequenas comunidades. Ela entende que o surgimento de novos movimentos alargou o campo de possibilidades de participação leiga e, por isso, os trabalhos de CEBs diminuíram:

Não é que não tenha; porque o povo fala assim “ah, não tem CEBs". Tem sim, porque tem setores, né? São as pequenas comunidades... Ainda tem setores que refletem, reflete campanha da fraternidade, reflete o natal, aí agora tá refletindo esse material do círculo bíblico. Então, ainda tem ... tem pessoas firmes na caminhada. Mas, assim, a Igreja foi vivendo outros momentos também né. Depois veio os pentecostais, depois chegou a Renovação. Parece que os trabalhos deram uma caída. Foi muito pressão em cima da Teologia da Libertação também né. Então, eu acho que isso aí prejudicou um pouco. ${ }^{60}$

A Teologia da Libertação (TdL), mencionada na entrevista, foi um movimento de intelectuais religiosos que surgiu no final dos anos 1960 no contexto latino-americano. Os primeiros esforços de sistematização dessa teologia vieram do teólogo peruano Gustavo Gutiérrez, com a obra Teologia da Libertação: perspectivas (1971), considerada, "ainda hoje, um dos marcos de fundação da Teologia da Libertação" ${ }^{6}$ No Brasil, é possível mencionar Frei Betto, Leonardo Boff, Clodóvis Boff e Carlos Mesters como exemplos de teólogos da libertação que participaram do movimento e contribuíram para a sistematização e afirmação do mesmo. Diferente da teologia dita tradicional, a teologia da libertação aderiu à teoria de matriz marxista para refletir sobre as condições sociais dos indivíduos marginalizados pela sociedade. Além desse aspecto teórico, alguns setores da Igreja Católica no Brasil - como foi o caso de alguns bispos, D. Paulo Evaristo Arns e D. Pedro Casaldáliga - buscaram colocar em prática as propostas apresentadas pelos teólogos da libertação, ou seja, articular ações que fossem capazes de

59 Entrevista concedida por Lucely para a entrevistadora em oI/o8/2019.

6o Entrevista concedida por Helena para a entrevistadora em 31/07/2019.

6I VALÉRIO, Mairon Escorsi. O continente pobre e católico: o discursos da teologia da libertação e a reinvenção religiosa da América Latina (1968-1992). 354 f. Tese (Doutorado em História) - Universidade Estadual de Campinas, Campinas, 20I2, p. I. 


\section{REVISTA ANGELUS NOVUS}

auxiliar as pessoas a refletirem a realidade em que viviam e promover atitudes de libertação frente às situações de opressão. Nesse sentido, segundo Mairon Escorsi Valério, a TdL encontrou nas CEBs um espaço oportuno e fértil, dado o momento de grandes dificuldades políticas pelo qual passava a América Latina:

(...) A teologia da libertação vai se voltar para as CEBs como espaço privilegiado de conscientização e mobilização popular principalmente a partir dos anos 1970, quando (...) se generaliza no cone sul da América Latina as ditaduras militares e se fecham muitos espaços de atuação da militância laica católica, além do influxo institucional interno decorrente da ascensão de bispos conservadores no comando do CELAM [Conferência Episcopal Latinoamericana] em $1973 .{ }^{62}$

Por fim, é válido destacar que os momentos de silêncios também entraram nas análises das entrevistas. $\mathrm{O}$ não-dito não se trata apenas de esquecimento por parte da colaboradora; faz parte da construção da narrativa e da seleção das lembranças. É preciso levar em consideração que alguns acontecimentos vivenciados pelas entrevistadas podem ter sido traumáticos, intimidadores ou irrelevantes, como a perda de pessoas ou a desigualdade de gênero, narrados somente após o encerramento da entrevista. Por isso não entraram de forma explícita nas conversas, mas por meio de gestos, uma respiração ofegante, uma pausa longa ou um choro também marcaram as narrativas. Ademais, notou-se que a gravação das entrevistas provocaram um sentimento de cuidado com o que estava sendo dito, por isso, outras questóes como o afastamento dos padres ex-assessores das CEBs e críticas aos novos movimentos que surgiram dentro da Igreja Católica foram mencionadas quando do desligamento do gravador de voz.

\section{Considerações finais}

A investigação histórica tradicional deixou à margem dos debates os processos históricos nos quais as mulheres também foram protagonistas: "É difícil pensar como a história construiu barreiras tão fortes que excluíram as mulheres enquanto objeto de conhecimento histórico". ${ }^{63}$

O trabalho de Michelle Perrot, já citado no texto, possui enorme importância para pesquisas sobre a História das Mulheres. Para este trabalho, especificamente, as

62 VALÉRIO, Mairon Escorsi. O continente pobre e católico: o discursos da teologia da libertação e a reinvenção religiosa da América Latina (1968-1992). 354 f. Tese (Doutorado em História) - Universidade Estadual de Campinas, Campinas, 20I2, p. 37.

63 TEDESCHI, Losandro Antonio. Alguns apontamentos sobre história oral, gênero e história das mulberes. Dourados-MS: UFGD, 2014, p. 17.

$22 \cdot$ ano XII, n. I7, 202I • ISSN 2I79-5487 
reflexões da autora contribuíram de forma significativa para se pensar o papel desempenhado pelas mulheres nos eventos históricos e os significados que eles produzem no universo feminino.

Nessa perspectiva, a pesquisa procurou mostrar como as experiências das mulheres foram importantes para o conhecimento dos trabalhos desenvolvidos pelas Comunidades Eclesiais de Base junto aos setores marginalizados da sociedade, para a apreensão do próprio desenvolvimento das CEBs em contexto específico e para a reflexão sobre o significado individual e coletivo que tais experiências proporcionaram para esse universo feminino.

Observou-se que as ações desenvolvidas pelas CEBs na diocese não são restritas ao campo da religião. Elas estão presentes em vários setores da sociedade, como nos espaços de poder público, nas entidades civis, nas escolas e em organizações nãogovernamentais. Sem deixar de lado a marca religiosa, as CEBs procuraram atuar de modo incisivo na reivindicação de melhores condições de vida, de emprego, moradia e alimentação para aqueles(as) que mais necessitavam. Entretanto, é importante destacar, apesar de não ter sido uma questão abordada no artigo (mas que pode ser trabalhada futuramente), que as CEBs, de uma maneira geral, surgem com um objetivo inicial de resolver um problema sobre a escassez de sacerdotes, no final dos anos 1950. ${ }^{64}$

Além disso, notou-se que na Diocese da Campanha (MG), como já mencionado, as Comunidades Eclesiais de Base sempre foram coordenadas por mulheres. Nesse bispado as CEBs caminham junto com outras pastorais e movimentos, promovendo o diálogo e articulando ações conjuntas. Mesmo que já tenham enfrentados conflitos com autoridades civis e eclesiásticas, é possível observar várias continuidades do movimento, exemplo notório é a Romaria do Trabalhador. Percebeu-se, também, que a mudança de bispos implica diretamente no relacionamento que se estabelece com os membros das Comunidades Eclesiais de Base, e que o clero da diocese possui posturas diversificadas no que se refere ao apoio e incentivo aos trabalhos propostos. Ademais, vale destacar que a pesquisa mostrou que as CEBs da Diocese da Campanha (MG) já estabeleceu vários vínculos com povos indígenas e com o MST. Isso revela que diálogo entre Igreja (ainda que não seja no âmbito institucional), movimento social e povos indígenas fazem-se presentes no bispado e são fundamentais para a defesa de direitos sociais.

Por fim, as mulheres entrevistadas colocaram-se em inteira disposição para a pesquisa. Compartilharam a vida, as experiências e os caminhos percorridos em uma atitude de profunda gratidão com uma investigação inédita dentro da Diocese da

64 VALÉRIO, Mairon Escorsi. O continente pobre e católico: o discursos da teologia da libertação e a reinvenção religiosa da América Latina (1968-1992). 354 f. Tese (Doutorado em História) - Universidade Estadual de Campinas, Campinas, 2012, p. 35 . 
REVISTA ANGELUS NOVUS

Campanha (MG). Acredita-se que, apesar de essas mulheres já possuírem reflexões sobre o significado que as vivências proporcionaram, a pesquisa contribuiu para que elas repensassem o lugar que ocuparam por muito tempo na igreja e o lugar que ocupam hoje, também, na sociedade civil.

Nessa perspectiva, conforme discorre Tedeschi, compreende-se que investigações desse tipo auxiliam em uma percepção ampliada do modo como os sujeitos históricos estiveram envolvidos com questões de seu tempo a partir de uma ótica que lhes é própria, e não formulada por terceiros. 